\title{
Customer Relationship Marketing
}

\section{Merlin Stone, Neil Woodcock and Liz Machtynger}

Kogan Page; 2000; ISBN 074942700 0; paperback; £14.99

In recent years there have been a plethora of books published in the relationship marketing area - more recently, the emphasis in published works has shifted towards 'relationship management' and to some degree this book moves in this direction (despite its title).

On first reading it is difficult to understand who the book and thus the authors themselves are trying to build a relationship with - it is not an academic text but more of a prompt of activities to build relationships between practitioner and customer. Thus the book would not sit comfortably in an academic context, but would clearly be of use to the practitioner consultant in their early stages of understanding and building relationships. In some senses the book is not written to be critical or indeed inform but more 'How To Do'.
The book is built around the practices of the individual authors who as consultants have been able to try and test the approaches recommended. This approach is evidenced by the very few authoritative references used throughout the text. The consequence of this is that the book has, basically, an inquesting approach to 'customer relationship marketing' at a time when the concept/practice is increasingly being questioned and possibly being found out, ie is it simply sales management in disguise for someone studying relationship marketing? In an academic context this book would be found wanting, in the practitioner context it is likely to be a useful 'aide memoire'.

Dr John Pallister Cardiff Business School 